\title{
Mesoporous zeolites as efficient catalysts for oil refining and natural gas conversion
}

\author{
Jie ZHU ${ }^{1,2}$, Xiangju MENG ${ }^{1}$, Fengshou XIAO $(\bowtie)^{1}$ \\ 1 Department of Chemistry, Zhejiang University, Hangzhou 310028, China \\ 2 College of Biological, Chemical Sciences and Engineering, Jiaxing University, Jiaxing 314001, China
}

(C) Higher Education Press and Springer-Verlag Berlin Heidelberg 2013

\begin{abstract}
Zeolites have been regarded as one of the most important catalysts in petrochemical industry due to their excellent catalytic performance. However, the sole micropores in zeolites severely limit their applications in oil refining and natural gas conversion. To solve the problem, mesoporous zeolites have been prepared by introducing mesopores into the zeolite crystals in recent years, and thus have the advantages of both mesostructured materials (fast diffusion and accessible for bulky molecules) and microporous zeolite crystals (strong acidity and high hydrothermal stability). In this review, after giving a brief introduction to preparation, structure, and characterization of mesoporous zeolites, we systematically summarize catalytic applications of these mesoporous zeolites as efficient catalysts in oil refining and natural gas conversion including catalytic cracking of heavy oil, alkylation, isomerization, hydrogenation, hydrodesulfurization, methane dehydroaromatization, methanol dehydration to dimethyl ether, methanol to olefins, and methanol to hydrocarbons.
\end{abstract}

Keywords mesoporous zeolite, catalysis, oil refining, natural gas conversion

\section{Introduction}

Microporous crystalline aluminosilicate zeolites are widely used in petrochemistry and fine-chemical industry because of their large surface area, high adsorption capacity, high thermal and hydrothermal stabilities, strong acid sites within their defined micropores, and shape-selectivity in catalysis [1-3]. However, zeolites with sole micropores are imposed by severe mass-transfer constraints, which results

Received November 29, 2012; accepted March 29, 2013

E-mail: fsxiao@zju.edu.cn in poor catalytic performance (such as lifetime and convention) in bulky substrate catalytic reactions [2-5]. Ordered mesoporous materials such as MCM-41 [6,7] and SBA-15 [8,9] with good mass transfer have once been expected to solve this problem. Unfortunately, compared with zeolites crystals, poor hydrothermal stability and weak acidity of these mesostructured materials hinder their catalytic applications in petrochemical chemistry $[1,2,10]$ due to the amorphous nature of the mesoporous walls. The strategies for improving hydrothermal stability of ordered mesoporous materials have been developed by partly crystallization of mesoporous walls via the addition of assynthesized zeolitic seeds solution in the synthesis procedure [11-14] or employing "high-temperature synthesis" routes $[15,16]$. However, the thus obtained materials are still insufficient for the catalytic application in industrical processes $[17,18]$. To solve these problems, many efforts have been devoted to synthesize nanosized zeolites $[19,20]$, ultralarge pore zeolites, and hierarchical mesoporous zeolites. Nanosized zeolites can offer more active sites in catalysis compared with conventional zeolites due to their larger external surface area, but they are difficult to be separated from the reaction mixture or catalysis system $[19,20]$. Ultralarge pore zeolites (such as UTD-1 [21], VPI-5 [22], ITQ-33 [23], JDF-20 [24], ITQ37 [25], and ITQ-43 [26]) have been regarded as ideal candidates for improving the mass transfer and catalytic conversion of bulky molecules, but special and high-cost organotemplates hinder their catalytic applications in industry. Recently, great efforts have been put forth to prepare mesoporous zeolites by creating mesopores into the zeolite crystals [17,27-31], which combines the advantages of mesostructured materials (fast diffusion and accessible for bulky molecules) and microporous zeolites (strong acidity and high hydrothermal stability) instead of upgrading their individual performances in catalytic reactions [32]. In this review, we briefly summarize the preparation, characterization and catalytic 
applications of mesoporous zeolites as efficient catalysts in oil refining and natural gas conversion.

\section{Synthesis}

\subsection{Post-synthesis treatments}

Mesoporosity can be introduced into the zeolite crystals through post-synthesis treatments including steaming [33] and leaching methods with acidic or basic media $[34,35]$. However, post-synthesis treatments always result in a significant reduction of zeolite crystallinity and the formation of amorphous aluminosilicate fragments in disordered and uncontrolled mesopores, which could negatively affect catalytic performance [27].

\subsection{Templating strategies}

Mesoporous zeolites with good crystallinity can be prepared employing mesoscale templates, which could be achieved by "hard" or "soft" templating strategies $[27,29,30]$. In hard-templating strategies, mesopores can be "duplicated" into zeolite crystals directly by using the secondary mesoscale templates such as carbon nanoparticles [36-38], carbon nanotubes [39,40], carbon nanofibers [41], carbon aerogels [42-45], and mesoporous carbons [46-53]. In addtion, some inorganic nanoparticles such as nano-sized $\mathrm{CaCO}_{3}$ can also be used as hard templates for synthesizing mesoporous zeolites [54]. Many mesoporous zeolites including FAU, MFI, BEA, LTA, LTL, MEL and MTW framework types can be successfully synthesized by using these hard templates. Notably, most mesopores in these cases are disordered and unopened. Recently, Tsapatsis' group [49-51] prepared a series of ordered mesoporous zeolites (3Dom-i zeolite) such as Silicalite-1, ZSM-5, beta, Y, A and L by using three dimensional ordered mesoporous carbons (3Dom carbon) as mesoscale templates (Fig. 1).

In soft templating strategies, mesopores could be successfully introduced into zeolite crystals directly because there are an interaction between the mesoscale soft templates and the aluminosilicate species. In 2006, Xiao et al. [55] firstly reported the synthesis of mesoporous beta zeolite by using the cationic polymers as mesoporedirecting agents. Subsequently, Choi and Srivastava et al. [56-58] synthesized mesoporous ZSM-5 and A zeolites by using an amphiphilic organosilicate as mesopore-directing agent. Later in the same year, mesoporous ZSM-5 zeolite was also prepared by using a silylated polyethylenimine as mesopore-directing agent [59]. After then, mesoporous zeolites have been widely investigated and the most used templates are polymers, long chain organosilicates, and amphiphilic surfactants. For example, mesoporous ZSM11 templated by polyvinyl butyral [60], mesoporous Y templated by long chain organosilicates [61], and mesoporous ZSM-5 templated by CTAB or F127 or P123 $[62,63]$ have been reported. More recently, there are a breakthrough progress in the synthesis of mesoporous zeolites with ordered mesopores by using soft template strategy. Ryoo' group [64-66] designed a kind of bifunctional surfactants, such as $\mathrm{C}_{22} \mathrm{H}_{45}-\mathrm{N}^{+}\left(\mathrm{CH}_{3}\right)_{2}-$ $\mathrm{C}_{6} \mathrm{H}_{12}-\mathrm{N}^{+}\left(\mathrm{CH}_{3}\right)_{2}-\mathrm{C}_{6} \mathrm{H}_{13} \quad\left(\mathrm{C}_{22-6-6}\right)$ and $\mathrm{C}_{18} \mathrm{H}_{37}-$ $\mathrm{N}^{+}\left(\mathrm{CH}_{3}\right)_{2}-\mathrm{C}_{6} \mathrm{H}_{12}-\mathrm{N}^{+}\left(\mathrm{CH}_{3}\right)_{2}-\mathrm{C}_{6} \mathrm{H}_{12}-\mathrm{N}^{+}\left(\mathrm{CH}_{3}\right)_{2}-\mathrm{C}_{18} \mathrm{H}_{37}$ $\left(\mathrm{C}_{18-6-6-18}\right)$, which can direct the formation of zeolite structures on the mesoporous and microporous length scales simultaneously, yielding ZSM-5 zeolite nanosheets with a thickness $(2 \mathrm{~nm})$ of only a single unit cell (Fig. 2) or ordered mesoporous zeolites with hexagonal mesophase and MFI-like zeolite framwork, respectively. Xiao's group [67] recently designed a new type of polymer polystyrene4-vinyl pyridine (PSt-co-P4VP), which can be used as the new polymer template for successfully synthesizing mesoporous ZSM-5 zeolite with $b$-axis-aligned mesoporous channels.

\section{Catalysis}

Mesoporous zeolites can be widely used as catalysts or supports in petrochemistry and fine-chemical synthesis such as cracking, alkylation, isomerization, hydrogenation

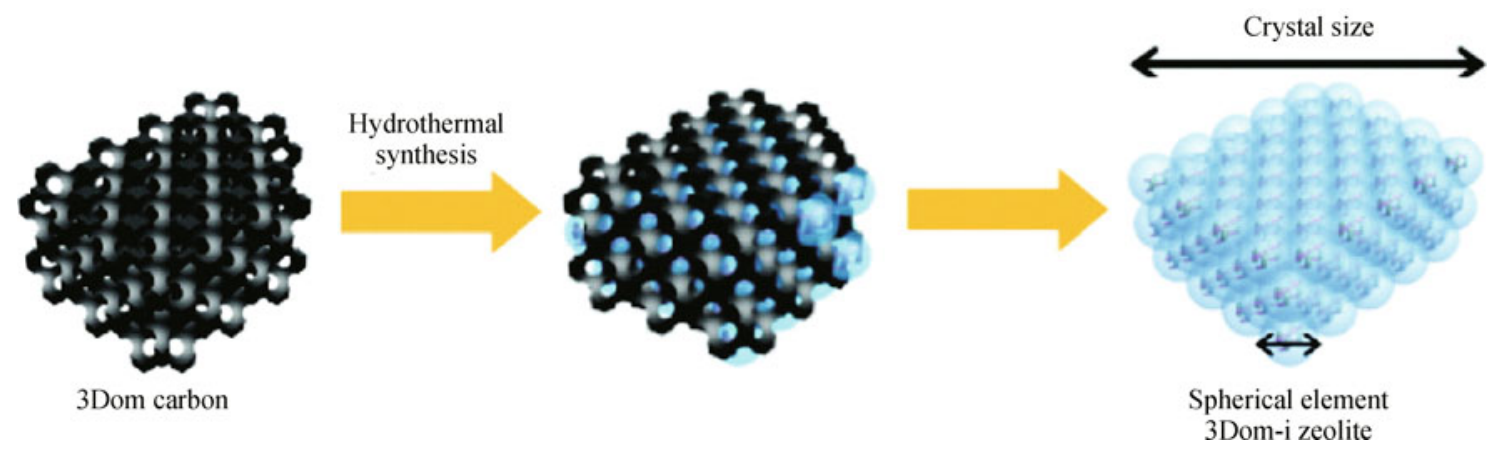

Fig. 1 Schematic illustration of 3Dom-i zeolite templating from 3Dom carbon. Reproduced by permission of Ref [51]. Copyright 2011 American Chemical Society 

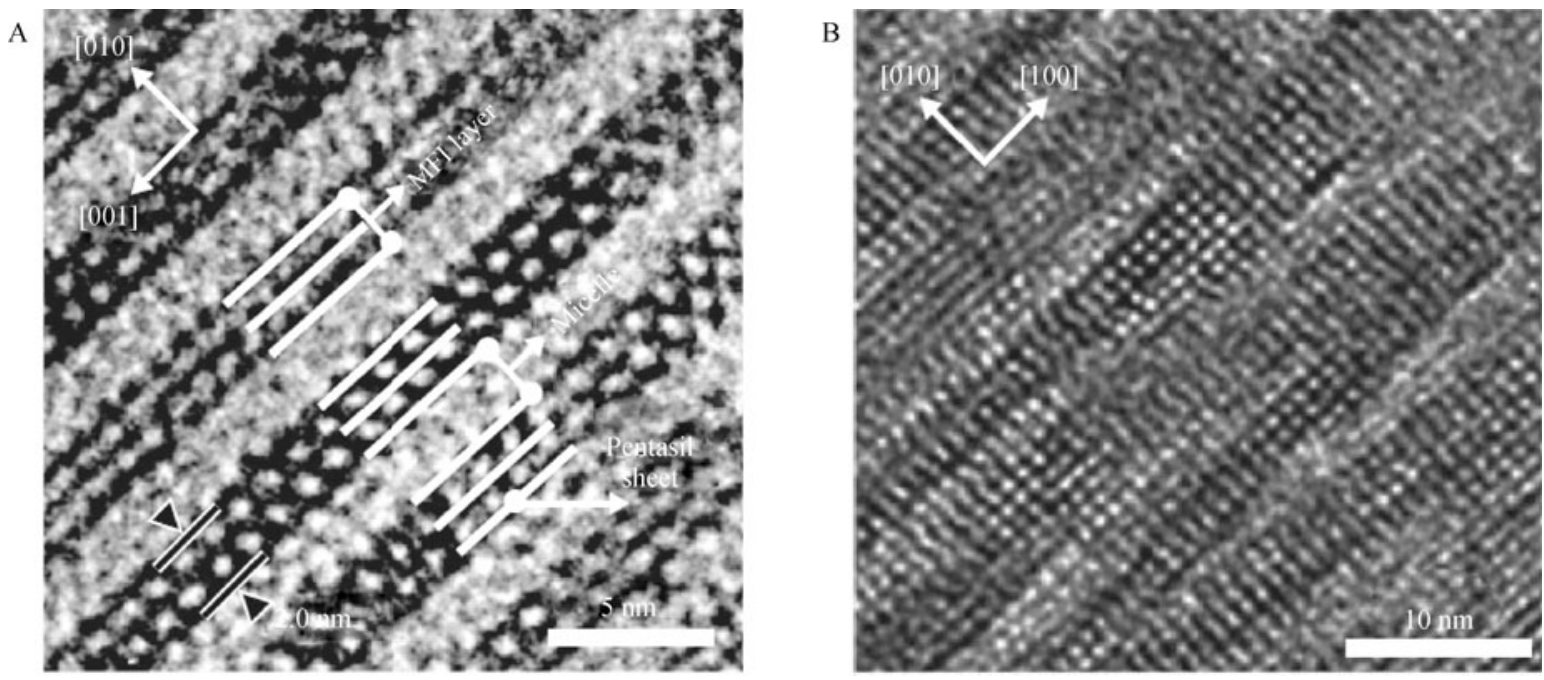

Fig. 2 HRTEM of as-synthesized (a) and calcined (b) MFI nanosheet templated from $\mathrm{C}_{22-6-6}$ surfanctant. Reproduced by permission of Ref. [64]. (Copyright 2009 Nature Publishing Group)

and hydrodesulfurization, methane dehydroaromatization, methanol dehydration to dimethyl ether, methanol to olefins (MTO), and methanol to hydrocarbons (MTH).

\subsection{Cracking reactions}

Fluid catalytic cracking (FCC) process is very important in industry because a huge amount of heavy hydrocarbon feedstocks can be further cracked into more valuable light oils. In these processes, USY with mesoporosity is widely used as the active component of the FCC catalysts. The introduction of mesoporosity in Y-zeolite by steaming and acid or base leaching can enhance the cracking activity of zeolite $\mathrm{Y}$ despite the acidic properties are modified by dealumination [1,28]. Kung et al. [68] concluded that minimizing diffusion restraints by the introduction of mesoporosity could be very important to increase rates of dimeric and oligomeric cracking reactions, which serve as an alternative explanation to highly active single sites. This explanation can be supported by that smaller ZSM-5 crystallites reduced the diffusion restraints and showed better catalytic activity than the parent samples for the cracking of linear or branched paraffins [69]. In a recent report by Garcia-Martinez et al. [70], mesostructured Y zeolites with well-controlled mesoporosity and high hydrothermal stability were prepared by a surfactantassisted method and used in the FCC process. These mesostructured Y-zeolites produced significantly more gasoline and light cycle oil (LCO) as well as less bottoms and coke, because the presence of mesopores allows larger molecules in the vacuum gas oil (VGO) to access the active sites within the zeolite crystals. Tan et al. [71] synthesized a bimodal micro-mesoporous aluminosilicate by assembling preformed zeolite $\mathrm{Y}$ nanoclusters using a triblock polymer as template. This micro-mesoporous material produced light oil fraction in higher yield (53\%) than the conventional $\mathrm{Y}$ catalyst ( $40 \%$ yield) in catalytic cracking of heavy oil.

In addition, mesoporous zeolites such as ZSM-5 and beta can be used as additives in a commercial USY FCC catalyst for imporving the catalytic activity and selectivity toward light olefins. For example, the higher propylene yield of $12.2 \mathrm{wt}-\%$ was achieved over E-USY/Meso-Z compared with $9.0 \mathrm{wt}-\%$ over E-USY/ZSM-5 [72], despite these additives did not affect the cracking activity of EUSY/additives at similar gas-oil yield. Mesopores in Meso-Z was stated as a key factor to the enhanced production of propylene, which suppressed secondary and hydrogen transfer reactions and offered easier transport and accessibility to active sites. Recently, ZSM-5 zeolites with small intracrystal mesopores $(2.2$ and $5.2 \mathrm{~nm})$ templated by organosilane polymer templates were also investigated in selective petroleum refining [73]. Compared with conventional ZSM-5, the two mesoporous zeolites display much higher reactivity and selectivity toward light olefins (gasoline) in cracking of VGO. The gasoline yield increased from $12 \%$ to $19 \%$ when using the mesoporous zeolites at the temperature of $823 \mathrm{~K}$, while the VGO conversion increased from $33 \%$ to $48 \%$, which was attributed to the olefin precursor formation in small intracrystal mesopores and subsequent olefin formation

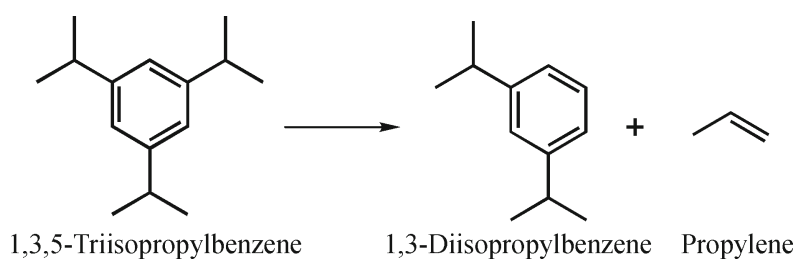

Scheme 1 Proposed reaction of 1,3,5-triisopropylbenzene cracking 
in micropores. These examples showed that mesoporous ZSM-5 zeolites as FCC catalysts have higher catalytic cracking performance than parent ZSM-5 zeolites.

The bulky 1,3,5-triisopropylbenzene (TIPB) is usually chosen as a typical substrate (Scheme 1) for the cracking of bulky aromatic hydrocarbons over mesoporous zeolites [74]. For example, mesoporous ZSM-5 prepared by a steaming-assisted conversion method shows a much higher initial conversion (98\%) than the conventional ZSM-5 (14\%) in cracking of TIPB [75]. Similarly, Zhou et al. [63] synthesized mesoporous ZSM-5 by using block copolymer surfactants as template in the steaming-assisted strategy, which showed much higher catalytic activity and remarkably imporved anti-deactivation performance in the cracking of TIPB (Fig. 3) compared to the conventional ZSM-5, due to the much increased external surface and shortened diffusion length in microporous networks provided by the mesoporous zeolites. Mesoporous ZSM11 zeolite shows a similar trend in the cracking of $1,2,4-$ trimethylbenzene, giving a higher conversion (67\%) compared with $43 \%$ for conventional ZSM-11 at a
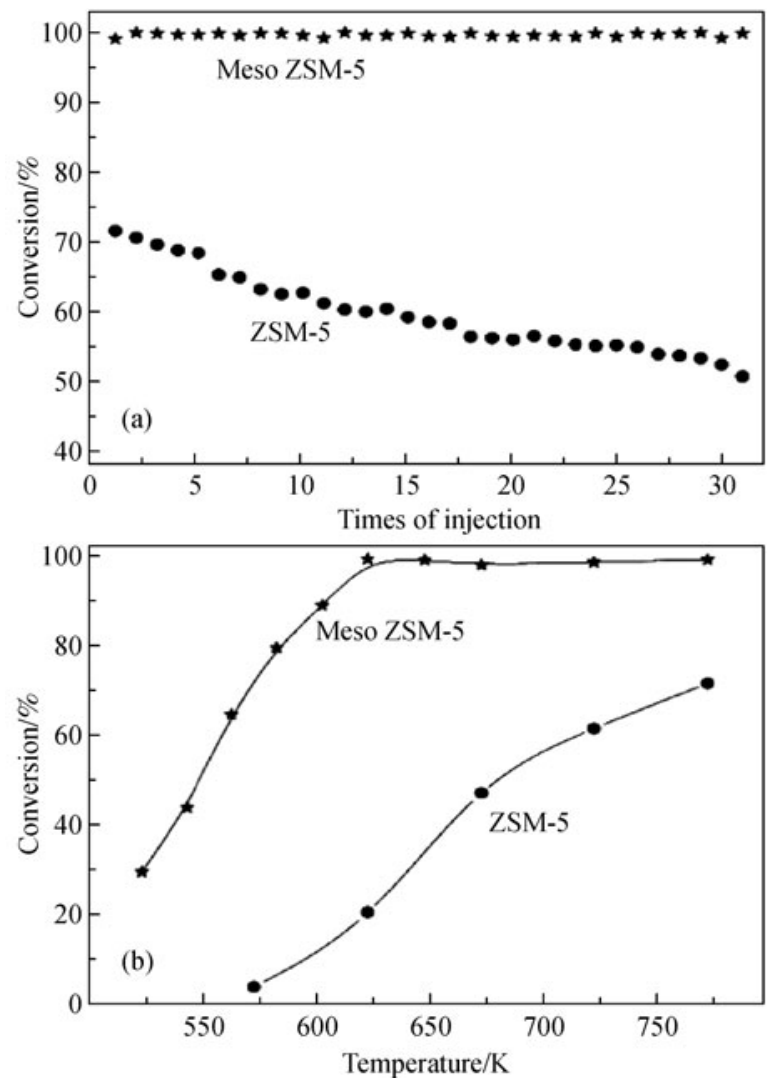

Fig. 3 Catalytic properties of conventional ZSM-5 and meso ZSM-5 employed in the cracking of TIPB (1,3,5-triisopropylbenzene) as a probe reaction: (a) deactivation behavior at $500^{\circ} \mathrm{C}$, and (b) catalytic activities (conversions) at different temperatures. Reproduced by permission of Ref [63]. (Copyright 2011 American Chemical Society) relatively low temperature of $350^{\circ} \mathrm{C}$ [60]. Mesopores in ZSM-11 zeolite crystals also leads to a higher activity of mesitylene isomerisation due to the fast diffusion of the bulky mesitylenes in the mesoporous, which reduced retention times and chance of cracking to form smaller products, but increased chance of mesitylene isomerisation.

Cracking of heavy linear alkanes such as $n$-hexadecane catalyzed by mesoporous zeolites has also received much attention. Zeolites with strong acidity, such as ZSM-5, ZSM-12, and ZSM-11 have been investigated in these reactions. For example, mesoporous ZSM-5 zeolite templated by carbons shows a significantly increased activity in heavy $n$-hexadecane cracking, and a much higher $n$-hexadecane conversion $(52 \%)$ than that of conventional ZSM-5 (17\%) [76]. After the zeolites were impregnated with platinum, their cracking activity increased significantly and the mesoporous ZSM-5 still displayed higher activity. Notably, there was a four fold increase in $n$-hexadecane isomerisation over mesoporous ZSM-5, which was explained by that the shorter retention time of the substrates in zeolite crystals with mesoporosity leads to less carcking and more isomerisation activity. Similarly, mesoporous ZSM-12 also showed higher activity compared with conventional ZSM-12 in $n$ hexadecane cracking [77]. Mesoporous ZSM-12 also exhibited higher coke-resistance performance, because mesopores increase the number of entry points to the microporous system as well as the overall surface area, and thereby increase the amount of coking needed to restrict its accessibility. In a different study, mesoporous zeolites with MEL structure type, such as silicalite-2 and ZSM-11, and conventional ZSM-5 were investigated and compared in $n$ hexadecane cracking [78].

In addition, the cracking of the polymers such as polyethylene or polypropylene are often tested over mesoporous zeolites to produce light olefins, and it is found that mesoporous zeolites are good catalysts for these reactions $[64,79]$.

\subsection{Alkylation reactions}

Alkylations of benzene and its derivatives are important reactions in oil refining and natural gas conversion. Mesoporous zeolites are more active in these alkylations reactions than conventional zeolites, due to the shorter diffusion path length in mesoporous zeolites. For example, mesoporous ZSM-5 prepared by carbon-templating showed higher conversion and ethylbenzene selectivity (18\% and $81 \%$, respectively) than the parent ZSM-5 (15\% and $73 \%$, respectively) (Scheme 2) [80,81]. Higher selectivity can be explained by the predominant level of monoalkylated product over mesoporous ZSM-5 resulting from a shorter diffusion path length in mesoporous zeolite crystal, while ethyl-benzene is difficult to diffuse in microporous zeolites leading to more polyalkylated 
products than those desired. Perez-Ramirez et al. [82] investigated the catalytic performance over mesoporous ZSM-5 obtained by desilication in liquid phase alkylation of benzene with ethylene, and highlighted a direct correlation between the catalytic activity in benzene alkylation and the hierarchy factor of ZSM-5, which was determined as the product $\left(V_{\text {micro }} / V_{\text {pore }}\right) \times\left(S_{\text {meso }} / S_{\mathrm{BET}}\right)$. The productivity of ethylbenzene during benzene alkylation over selected zeolites shows a linear dependence on the hierarchy factor. These results show that a sample only having a pronounced mesoporosity as well as a relatively preserved microporosity performed well in this reaction.

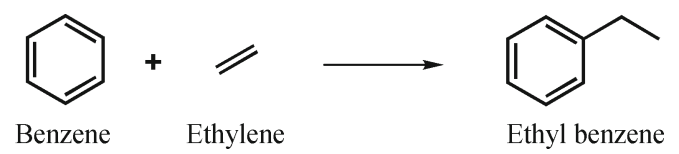

Scheme 2 Proposed reaction of benzene alkylation with ethylene

Xiao et al. [55] synthesized a mesoporous zeolite beta by using mesoscale cationic polymers as soft template, which was used as catalyst in alkylation of benzene with 2propanol. Mesoporous beta sample exhibited much higher activity and isopropylbenzene selectivity (both close to $100 \%$ ) than the conventional beta, and more importantly, a remarkably slow deactivation over the mesoporous sample could be also observed (Fig. 4). de Jong et al. [83,84] reported the catalytic performance over a seriers of mordenite zeolites by dealumination or/and desilication used as catalysts in liquid alkylation of benzene with

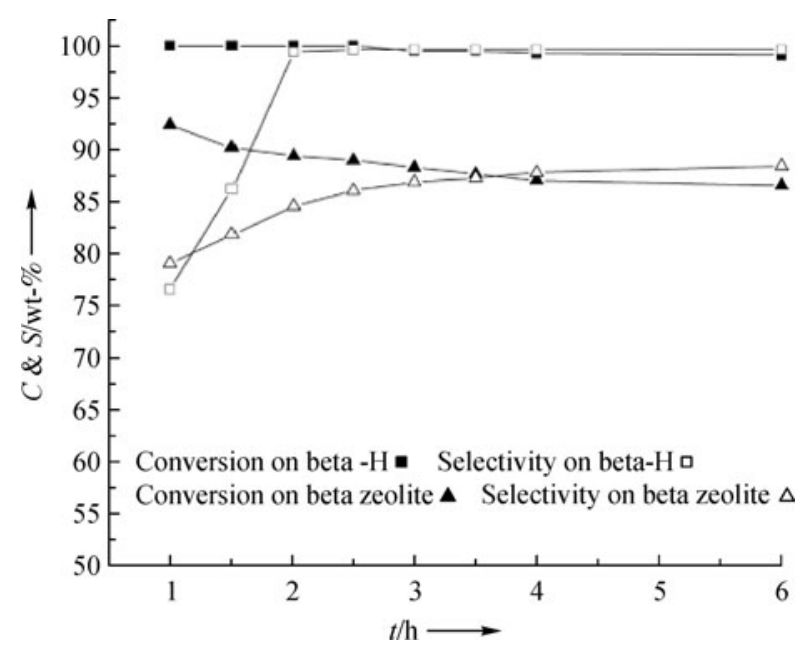

Fig. 4 Catalytic conversions $(C$. Wt-\%) and selectivities $(S$. wt-\%) in the alkylation of benzene with 2-propanol with various zeolites samples as a function of reaction time (Reaction temperature: $200^{\circ} \mathrm{C} ; 4: 1$ benzene/2-propanol; reaction pressure: 2.0 MP, weight hourly spare velocity (WHSV): $10 \mathrm{~h}^{-1}$ ). Reproduced by permission of Ref. [55]. (Copyright 2006 Wiley) propylene. Various catalytic effects such as Al-content, inter- and intracrystalline porosity, acid strength and the presence of extra-framework aluminum were investigated. The mordenite samples by dealumination showed a slightly improved activity and a selectivity towards cumene/di-isopropylbenzene, compared with the parent mordenite sample. However, a subsequent optimized desilication treatment resulted in a mesoporous catalyst displaying a significantly higher activity (up to 27 -fold increase) and an increased selectivity towards di- and triisopropylbenzene. The mordenite sample by desilication also displayed an excellent combined cumene/di-isopropylen benzene selectivity of $>99 \%$ arising from suppressed propylene oligomerization.

\subsection{Isomerization reactions}

\subsubsection{Conversion of $n$-butene to isobutene}

Isomerization of $n$-butene to isobutene catalyzed by zeolites is very valuable for producing low pollution gasoline additive of methyl tert-butyl ether (MTBE). Introduction of mesopores in zeolite crystals could improve the catalyst performance. An example is the use of fresh and steamed ferrierite (FER) catalysts in the isomerization of $n$-butene to isobutene [85]. The steamed FER catalyst with mesoporosity exhibited lower initial $n$ butene conversion but much higher selectivity of isobutene compared with the fresh catalyst. In a different report [86], mesoporous ferrierite zeolite prepared by recrystallization from alkaline solution in the presence of cetyltrimethylammonium bromide (CTAB) showed improved catalytic activity and selectivity in the isomerization of $n$-butene with respect to the parent ferrierite. The parent ferrierite gave 1-butene with $52 \%$ conversion while mesoporous ferrierite increased the conversion up to $67 \%$ and the isobutene selectivity from $48 \%$ to $61 \%$. Similarly, mesoporous TON zeolites prepared by desilication using $\mathrm{NaOH}$ also showed a significant increase of activity in $n$ butene isomerization [87]. The creation of mesopores in zeolite crystals improved the diffusion of butene molecules within the zeolite crystal and thereby increased the turn over frequency (TOF) of the protonic sites. The catalytic activities in isomerization of linear paraffins over mesoporous zeolite catalysts were listed in Table 1.

\subsubsection{Linear paraffins}

Hydroisomerization of linear paraffins towards highly branched products is an important reaction in upgrading of oils. Mesoporous zeolites were used as catalyst in hydroisomerization of various linear paraffins, usually showing much better catalytic performance compared with the parent sample [88-95]. These linear paraffins commonly include $n$-hexane, $n$-heptane, $n$-octane, $n$ - 
Table 1 Catalytic activities in isomerization of linear paraffins over mesoporous zeolite catalysts

\begin{tabular}{|c|c|c|c|c|c|}
\hline Substrates & Mesoporous zeolites & Synthesis strategies & Conversion $/ \%$ & Isomer selectivity/\% & Ref. \\
\hline$\overline{n \text {-Hexane }}$ & ZSM-5/MCM-41 & Recrystallization in base solution & $22(22)^{*}$ & $90(81)$ & {$[89]$} \\
\hline$n$-Hexane & $\begin{array}{c}\text { ZSM-5 } \\
\text { beta }\end{array}$ & Desilication & $\begin{array}{l}68(59) \\
73(53)\end{array}$ & $\begin{array}{l}97(96) \\
98(91)\end{array}$ & [90] \\
\hline$n$-Heptane & $\begin{array}{c}\text { ZSM-12 } \\
\text { beta }\end{array}$ & Hard template & $\begin{array}{l}38(10) \\
55(23)\end{array}$ & - & [91] \\
\hline$n$-Octane & ZSM-22 & Desilication & $78(67)$ & $75(<65)$ & [92] \\
\hline$n$-Octane & SAPO-11 & Soft template & $43(43)$ & $98(88)$ & [93] \\
\hline$n$-Octane & $\mathrm{Y}-\beta$ & Recrystallization & $52(14)$ & $76(54)$ & [94] \\
\hline$n$-Hexadecane & ITQ-6 & Delamination & $80(30)$ & $62(42)$ & [95] \\
\hline
\end{tabular}

*The catalytic data in brackets correspond to the activities or isomer selectivities over parent samples

hexadecane (Table 1). Typically, in $n$-octane hydroisomerisation, mesoporous zeolites with one dimensional framework type used as catalysts attracted much attention. For example, the mesoporous bi-functional Pt/ZSM-22 catalyst prepared by base treatment clearly showed better performance than its microporous parent, giving a higher monobranched isomer yield [92]. This superior activity is attributed to an increased number of accessible micropores in the mesoporous zeolite. Fan et al. [93] prepared a mesoporous SAPO-11 zeolite by using a tetradecylphosphoric acid (TDPA) template to create mesopores. Compared with the conventional SAPO-11, this mesoporous SAPO-11 had much higher external surface (165$\left.64 \mathrm{~m}^{2} \cdot \mathrm{g}^{-1}\right)$, mesoporous volume $\left(0.31-0.06 \mathrm{~cm}^{3} \cdot \mathrm{g}^{-1}\right)$ with the intracrystal mesopores of 4-7 nm and more medium and strong Bronsted acid sites $\left(165-76 \mu \mathrm{mol} \cdot \mathrm{g}^{-1}\right)$. In the hydroisomerization of $n$-octane, this mesoporous SAPO11-based catalyst showed superior isomerization activity, enhanced selectivity to dibranched products, and decreased cracking selectivity (Fig. 5). These results indicate that mesopores in zeolite catalyst enhance the catalytic performance in $n$-octane hydroisomerization. Similarly, the Y- $\beta$ zeolite composite with mesoporosity synthesized by using high silica $\mathrm{Y}$ zeolite as the precursor also showed an excellent hydrocracking activity and good hydroisomerization performance of $n$-octane [94]. Additionally, in the isomerizations of large hydrocarbons, such as $n$ hexadecane, mesoporous Pt/ITQ-6 was more active than $\mathrm{Pt} / \mathrm{FER}$, giving a higher ratio (2.1) of isomerisation to cracking products than Pt/FER (1.2) [95].

\subsubsection{Xylene}

The isomerization of $o$-xylene to $p$-xylene, a typical example of shape-selective catalysis by zeolites, is of great importance in petrochmical industry. $O$-xylene isomerization over mesoporous ZSM-5 prepared by desilication [96] showed higher conversion than the parent ZSM-5, owing to the reduced diffusion limitations. However, the selectivity of $p$-xylene decreased, more $m$-xylene formed, and the catalyst was rapidly deactivated, due to the deleterious effect of acidity on the external surface as a consequence of coking. These disadvantages could be reduced by washing the desilicated zeolite with acid to remove extra-framework aluminum (EFAl) species on the external surface for inhibiting the non-shape selective isomerization reaction [97]. The acid washed mesoporous ZSM-5 was more stable than parent ZSM-5 and untreated mesoporous ZSM-5, increasing the selectivity of $p$-xylene and the yield of $p$-xylene by two fold compared to parent ZSM-5.

\subsection{Hydrogenation and hydrodesulfurization}

Hydrogenation and hydrodesulfurization (HDS) are very important for removal of sulfur in gasoline and diesel fuels. Despite conventional zeolites show their advantages in these process, their pore size limitation inhibits their application in deep hydrogenation and hydrodesulfurization of diesel fuels. Mesoporous zeolite supported noble metal catalysts have been reported as good catalysts for hydrogenation of bulky aromatics and hydrodesulfurization of bulky 4,6-dimethyldibenzothiophene (4,6DMDBT) [98-100]. These catalysts showed excellent catalytic performance, giving much better activities than Pd loaded other supports such as $\gamma-\mathrm{Al}_{2} \mathrm{O}_{3}$, conventional zeolites (Hbeta and HZSM-5), and ordered mesoporous meterials (Al-MCM-41), which is attributed to the unique factor that these mesoporous zeolites combined the advantages of strong acidity and large external surface area in the samples.

Recently, Fu et al. [61] prepared a mesoporous Y zeolite (Y-M) by using a long chain organosilane surfactant as a soft tempate, followed by $\mathrm{Pd}$ loading ( $\mathrm{Pd} / \mathrm{Y}-\mathrm{M})$. Very importantly, $\mathrm{Pd} / \mathrm{Y}-\mathrm{M}$ displays excellent catalytic performance in HDS of 4,6-DMDBT. Compared with mesoporous beta $(80.0 \%)$ and ZSM-5 supported Pd catalysts $(73.4 \%)$ as well as commercial catalyst of $\gamma-\mathrm{Al}_{2} \mathrm{O}_{3}$ supported Pd catalyst (31.4\%), Pd/HY-M catalyst exhibited very high activity (97.3\%) in HDS of 4,6-DMDBT 

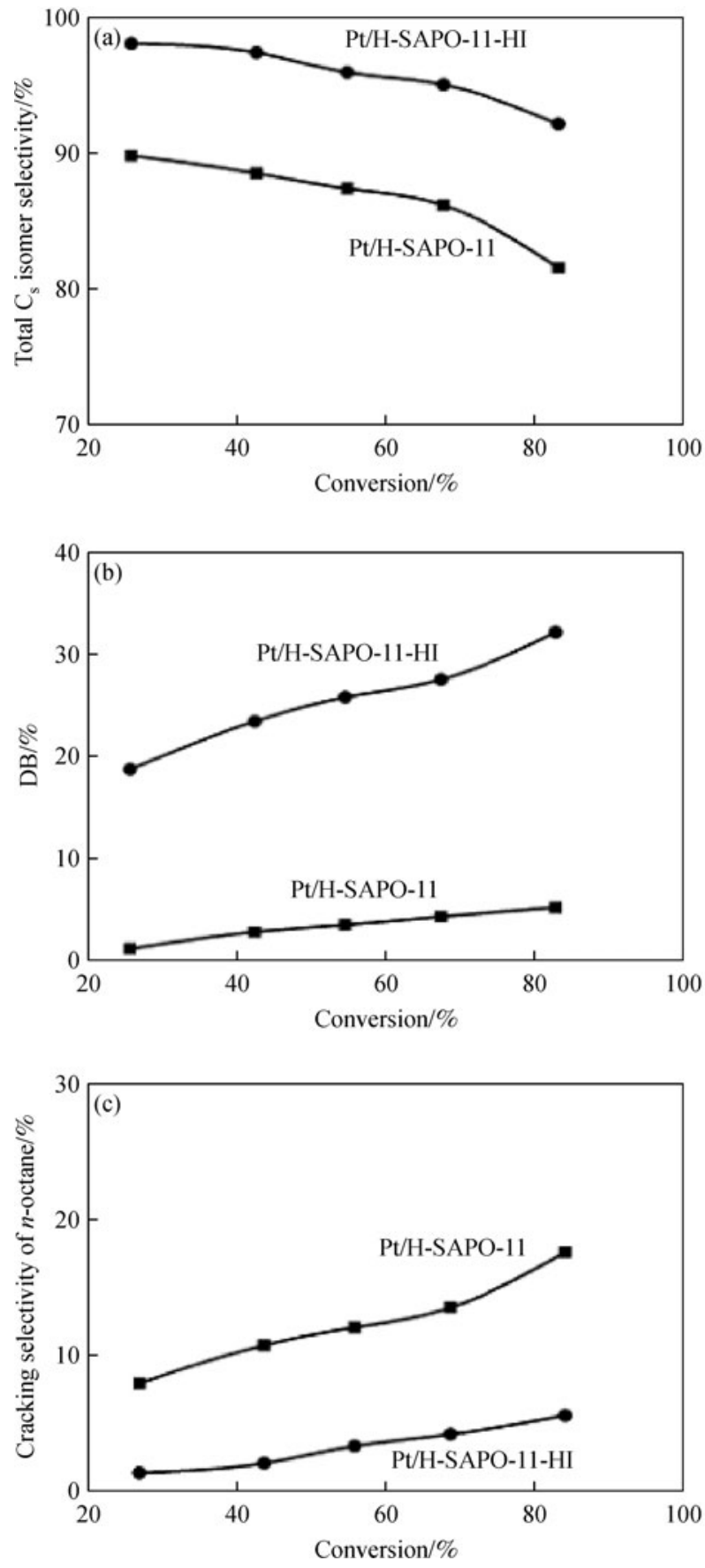

Fig. 5 Dependence of (a) the isomer selectivity, (b) the percentage of di-branched $\mathrm{C}_{8}$ isomers in total $\mathrm{C}_{8}$ isomers (denoted as $\mathrm{DB}$ ), and (c) the cracking selectivity of $n$-octane in $n$-octanehydroisomerization system on $n$-octane conversion over conventional $\mathrm{Pt} / \mathrm{H}-\mathrm{SAPO}-11$ and mesoporous $\mathrm{Pt} / \mathrm{H}-\mathrm{SAPO}-11-\mathrm{HI}$ catalysts. Reproduced by permission of Ref. [93]. (Copyright 2012 Elsevier)

(Fig. 6). The presence of mesoporosity in the zeolites play an important role for the contribution of catalytic activities.

In addition, even in the liquid-phase hydrogenation of benzene, a hierarchical mesoporous zeolite composite possessing beta-zeolite cores and Y-zeolite polycrystalline
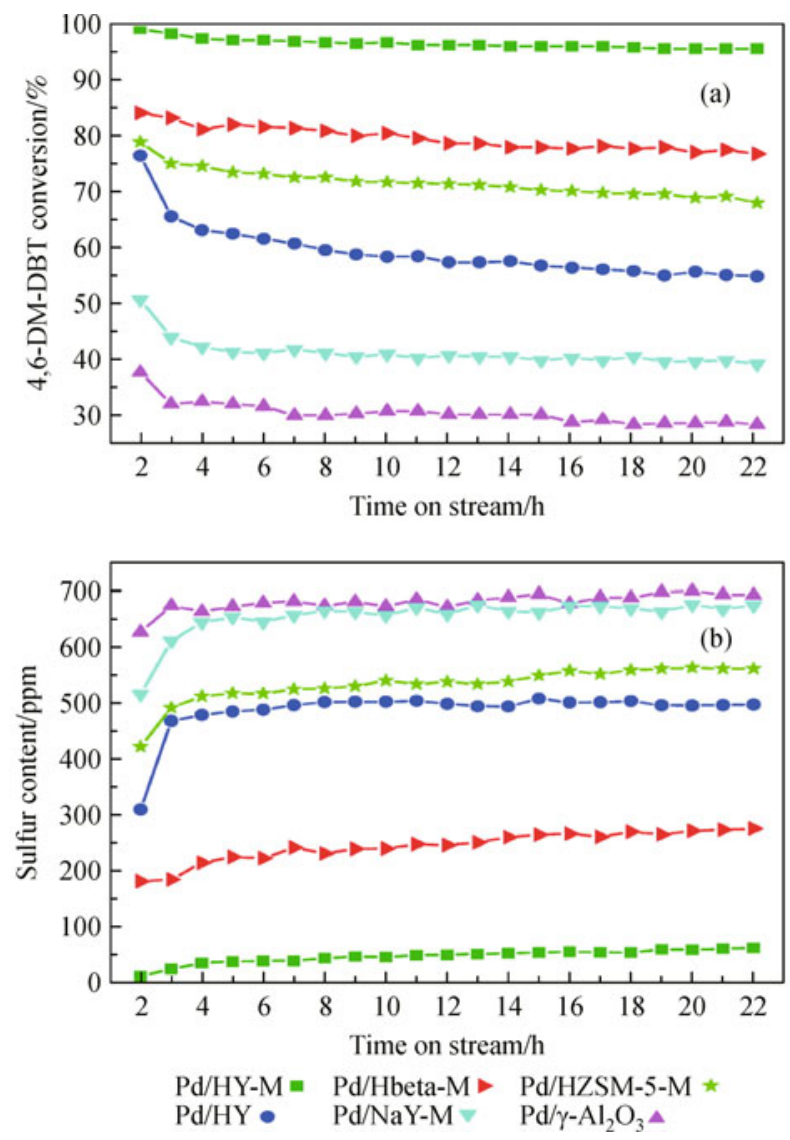

Fig. 6 Dependence of (a) the 4,6-DMDBT conversion and (b) the remaining sulfur content in 4,6-DMDBT-hydrogenation system on reaction time over Pd/HY-M, Pd/Hbeta-M, Pd/HZSM5-M, $\mathrm{Pd} / \mathrm{HY}, \mathrm{Pd} / \mathrm{NaY}-\mathrm{M}$ and $\mathrm{Pd} / \gamma-\mathrm{Al}_{2} \mathrm{O}_{3}$ catalysts. Reproduced by permission of Ref. [61]. (Copyright 2011 American Chemical Society)

shells (denoted as BFZ) also showed excellent catalytic performance [101]. The benzene conversion over H-BFZ supported $\mathrm{Ru}(3 \mathrm{wt}-\%)$ is much higher than those over parent $\mathrm{H}-\mathrm{Y}$ or $\mathrm{H}-\beta$-zeolites supported $\mathrm{Ru}$ catalysts, which is ascribed to the improved diffusion and acid accessibility as well as the enhanced $\mathrm{Ru}$ dispersion because of the introduction of hierarchical mesopores.

\subsection{Methane dehydroaromatization}

In natural gas conversion research, the non-oxidative methane dehydroaromatization (MDA) is one of valuable and challenging topics in both academia and industry. Mobased zeolite catalysts, e.g., Mo-ZSM-5 [102] have been often used as catalysts in this reaction. Su et al. [103] created mesopores in ZSM-5 zeolite by alkali treatment and found that the catalytic performance of mesoporous Mo-HZSM-5 catalyst in MDA had been enhanced. Recently, novel hierarchical mesoporous ZSM-5 was synthesized by using SBA-15 as the silica source, and showed good catalytic performance in the MDA reaction 
[104]. The mesopores reasonably assigned to intercrystalline voids between the French fries-like crystals provide easier access to the active sites in micropores, resulting in the higher $\mathrm{CH}_{4}$ conversion and the stronger cokingresistant performance. In one study reported by Martinez et al. [105], a bifunctional Mo/HZSM-5-BP catalyst for MDA was prepared by using a mesoporous HZSM-5 sample synthesized in the presence of carbon nanoparticles, and showed enhanced stability with time-on-stream compared with a Mo/HZSM-5, resulting in a higher and stable aromatics yield. This better tolerance to carbonaceous deposits of Mo/HZSM-5-BP could be attributed to the presence of the intracrystalline mesopores, allowing more coke to be formed while keeping a larger fraction of acid sites in the 10-ring channels active for aromatization. A similar result has also been confirmed by Kan et al. [106].

In addition, a nestlike hollow hierarchical mesoporous MCM-22 microspheres (MCM-22-HS) were synthesized by using carbon black as hard template and tested in the MDA reaction [107]. The Mo/HMCM-22-HS significantly improved methane conversion, benzene yield, and catalyst life (Fig. 7). The exceptional catalytic performance was attributed to the hollow and hierarchical mesoporous structure, which is favorable for the diffusion of larger molecular products, probably leading to significant improvement of the catalyst life.

All above these examples showed the presence of mesopores in zeolite catalysts in MDA reaction enhanced benzene yield and catalyst life.

\subsection{Methanol dehydration to dimethyl ether}

Dimethyl ether (DME) as a new synthetic fuel has attracted much attention due to its potential use as a substitute of diesel and liquefied petroleum gas. Generally, DME can be produced in a fixed bed reactor by methanol dehydration over porous solid acid catalysts such as zeolites. However, DME does not diffuse quickly enough in the sole micropore in zeolite, causing the catalyst to lose catalytic activity and selectivity quickly. Mesoporous zeolites, combining the strong acidity and hydrothermal stability of microporous zeolite with the fast mass transfer performance of mesoporous material, are also expected to be used for dehydration of methanol to DME to obtain
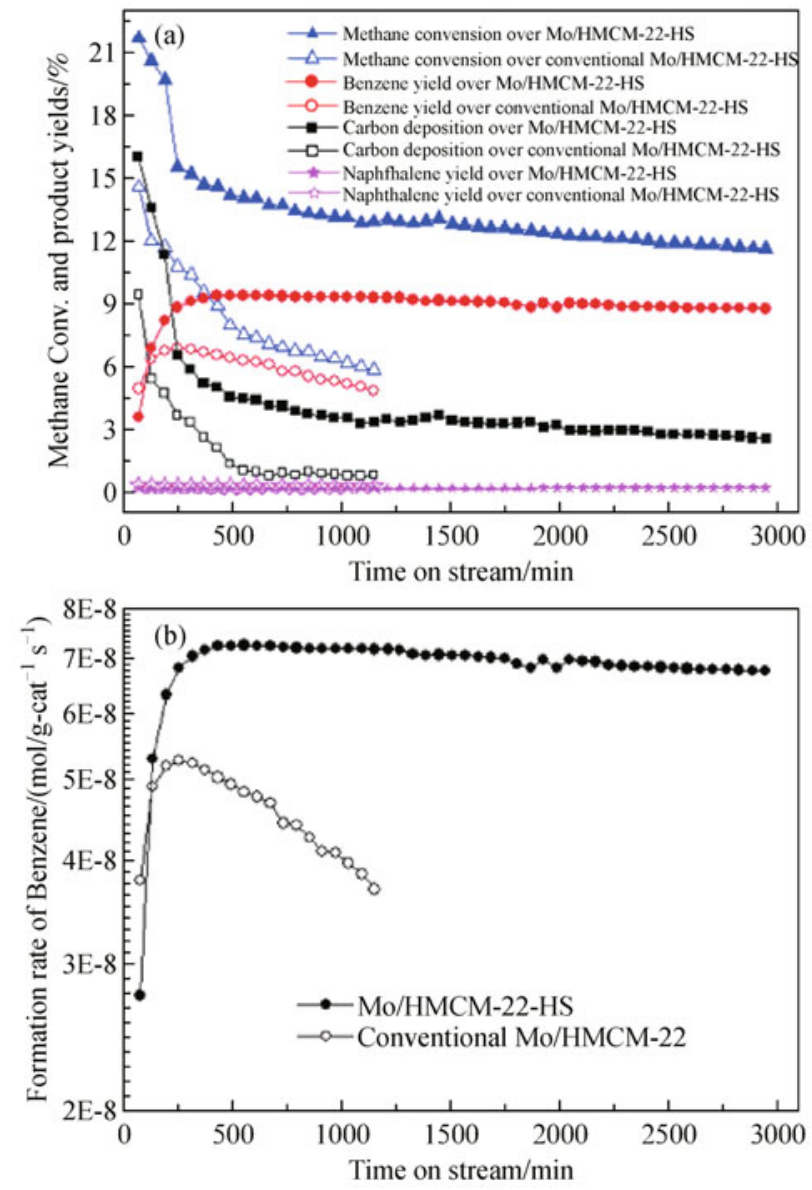

Fig. 7 (a) Catalytic performances of mesoporous Mo/HMCM-22-HS and conventional Mo/HMCM-22 catalysts in methane dehydroaromatization; (b) formation rates of benzene at $700^{\circ} \mathrm{C}$ on these two catalysts under space velocity of $1500 \mathrm{~mL} /(\mathrm{g} \cdot \mathrm{h})$. Reproduced by permission of Ref. [107]. (Copyright 2010 American Chemical Society) 


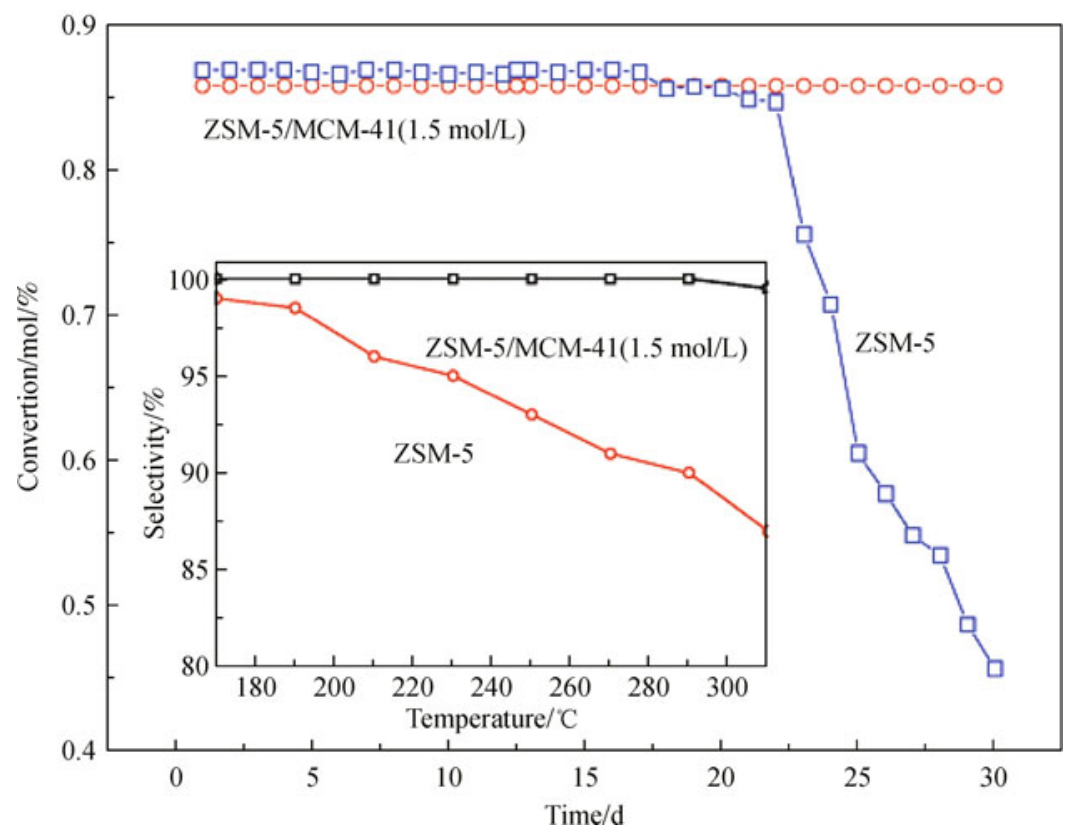

Fig. 8 Stability and selectivity in methanol dehydration over ZSM-5 and ZSM-5/MCM-41 composite alkali-treated by NaOH solution $1.5 \mathrm{~mol} / \mathrm{L}$. Reproduced by permission of Ref. [108]. (Copyright 2012 Elsevier)

an improved catalytic performance. For example, Tang et al. [108] reported that micro-mesoporous ZSM-5/MCM41 composites prepared by combining a microporous zeolite silica source with nano self-assembly methods showed an optimum activity $\left(X_{\mathrm{MeOH}}=86.6 \%\right), 100 \%$ DME selectivity and long catalyst life at $210^{\circ} \mathrm{C}$ in methanol dehydration to DME, much better than the parent ZSM-5 (Fig. 8).

Cho et al. [109] synthesized a mesoporous LTA zeolite by using organosilane surfactant as a mesopore-generating agent and ion-exchanged by $\mathrm{Ca}^{2+}$. The mesoporous $\mathrm{CaA}$ catalyst showed higher conversion of methanol, lower selectivity to hydrocarbons, and slower deactivation compared to the conventional $\mathrm{CaA}$ zeolite sample (Fig. 9) in methanol dehydration to DME. For example, the mesoporous $\mathrm{CaA}$ gave a $34 \%$ methanol conversion at $1 \mathrm{~h}$, and the selectivity of hydrocarbons was almost zero. However, under the same condition, the methanol conversion and hydrocarbon selectivity over the conventional $\mathrm{CaA}$ was $25 \%$ and $34 \%$ in methanol dehydration to DME, respectively.

\subsection{Methanol to olefins}

Methanol to olefins (MTO) is greatly important for solving the demand for light olefins. In the MTO process, Mei et al. [110] introduced the mesoporosity in high silica HZSM-5 by alkaline desilication and used the thus obtained zeolites as catalyst in methanol-to-propylene (MTP) reaction. The mesoporous HZSM-5 catalyst gave very high propylene selectivity (42.2\%) and propylene/ethylene ratio (10/1) (Fig. 10). Characterizations by various techniques show that these open mesopores are very helpful for enhancing the diffusion of the primary olefin products, in particular to propylene and butylene, thus inhibiting undesirable secondary reactions.

Hierarchical mesoporous SAPO-34 zeolite with high crystallinity and excellent hydrothermal stability was synthesized in the nanoscale confined environment provided by the natural layered material kaolin (Fig. 11) [111]. The mesoporous SAPO-34 catalyst showed significant enhancement of catalytic activity and selectivity in the MTO reaction. Interestingly, a supported SAPO-34 catalyst with an average size of $60 \mu \mathrm{m}$ was synthesized by a hydrothermal method on fully calcined kaolin microspheres pretreated with $4 \mathrm{wt}-\% \mathrm{NaOH}$ solution [112]. This new SAPO-34 catalyst remained the pretreated CKMs structure and had high microporous volume $\left(0.27 \mathrm{~m}^{3} \cdot \mathrm{g}^{-1}\right)$ and mesoporous volume $\left(0.30 \mathrm{~cm}^{3} \cdot \mathrm{g}^{-1}\right)$ with mesopores of $15.8 \mathrm{~nm}$, and thereby exhibited excellent catalytic performance with $100 \%$ methanol conversion, $90 \%$ light olefins selectivity, a long catalyst life, and strong mechanical stability at $450^{\circ} \mathrm{C}$.

\subsection{Methanol to hydrocarbons and methanol to gasoline}

Methanol to hydrocarbons (MTH) reaction plays an important role in the conversion of biomass, coal, natural gas, and $\mathrm{CO}_{2}$ to liquid hydrocarbon fuels, which can be tuned into production of gasoline-rich (methanol to 

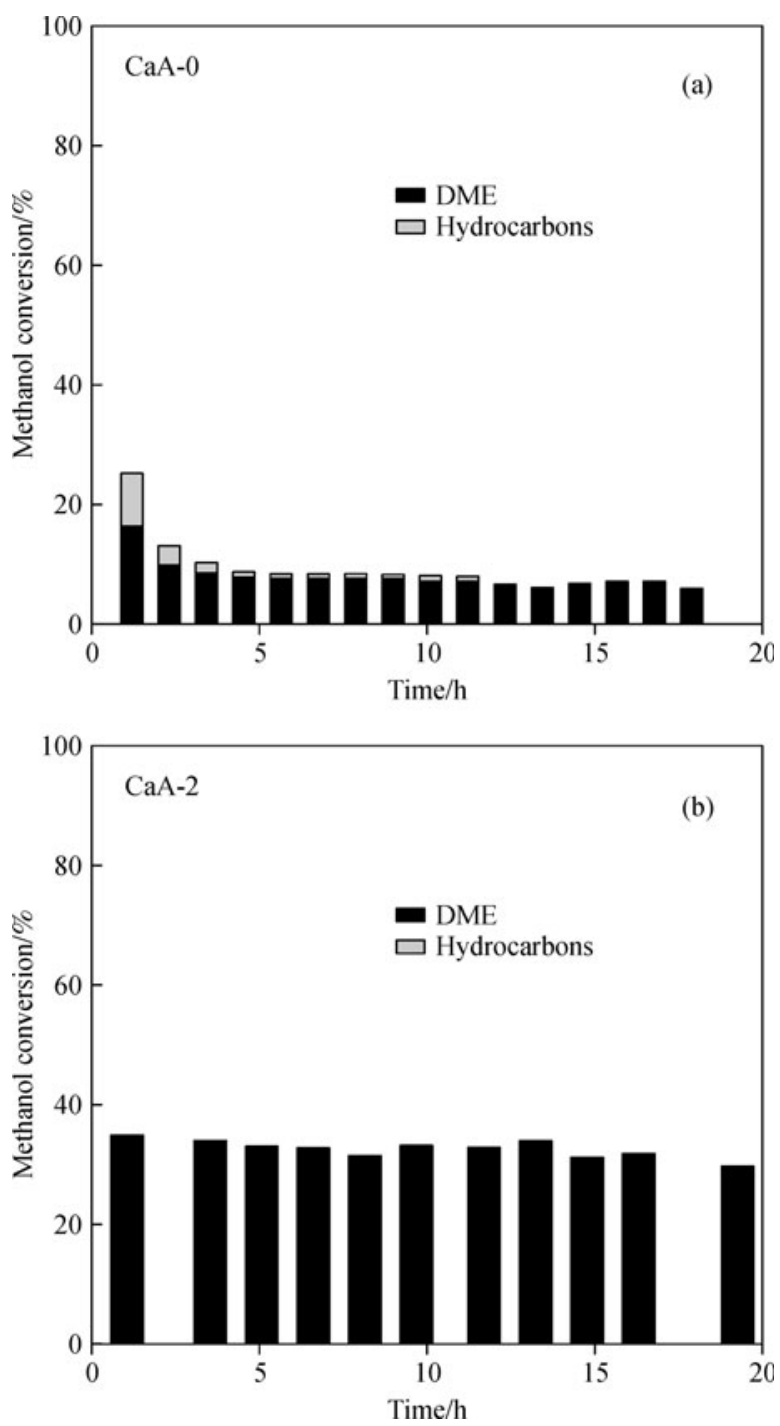

Fig. 9 Catalytic conversion of methanol to dimethyl ether (DME) over conventional CaA-0 (a) and mesoporous CaA-2 (b) zeolites at $400^{\circ} \mathrm{C}$. Methanol conversion was calculated by considering DME and hydrocarbons as converted products. Reproduced by permission of Ref. [109]. (Copyright 2009 American Chemical Society)

gasoline, MTG) or olefin-rich (methanol to olefins, MTO) product mixtures by proper choice of catalyst and reaction conditions [113]. Very importantly, mesoporous zeolites showed an increased catalyst life in MTH or MTG reactions than conventional zeolites catalyst.

Mesoporous ZSM-5 synthesized from various routes showed an improved catalyst life in MTG and MTH, compared to conventional ZSM-5 [64,114-121]. As a typical example, Choi et al. [64] reported that ZSM-5 nanosheet showed equivalent initial activity, but a significant increase in catalyst life (Fig. 12), compared to parent ZSM-5. Recent works confirm that there are strong correlations between the catalyst life and the external surface area of mesoporous zeolites in MTH and MTG reactions $[116,119]$.

\section{Summary}

The strategies for creating mesoporosity in zeolite crystals are briefly summarized. Very importantly, compared with conventional zeolites, the mesoporous zeolites exhibit excellent performance in oil refining and natural gas conversion such as cracking, hydrogenation and hydrodesulfurization of heavy oil, benzene alkylation, hydroisomerization, methane dehydroaromatization, methanol dehydration to dimethyl ether, methanol to olefins, and methanol to hydrocarbons. These phenomena are reasonably attributed to a fast diffusion and accessibility for reactants and products. These features are potentially important for applications of mesoporous zeolites in the future. 


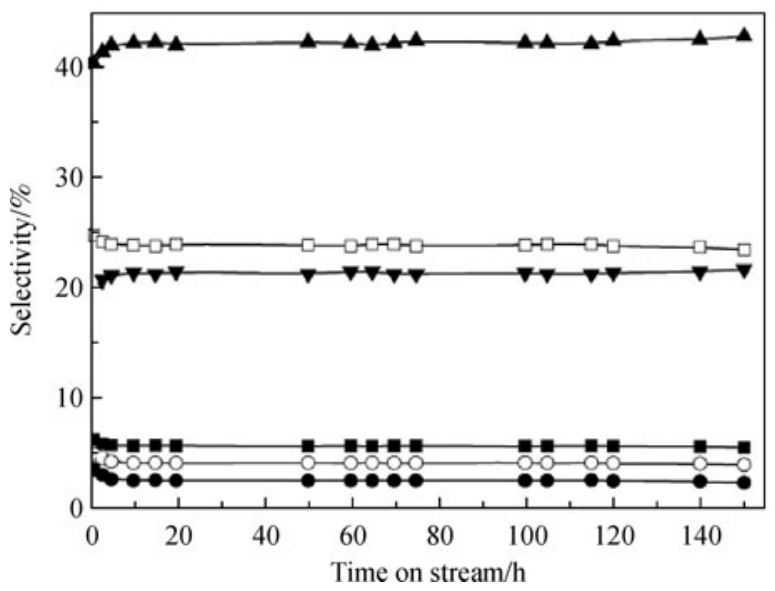

Fig. 10 Product selectivity of mesoporous HZSM-5 by alkaline treatment as a representative catalyst for MTP reaction as a function of time: $\mathrm{C}_{3} \mathrm{H}_{6}, \mathrm{C}_{2} \mathrm{H}_{4}, \mathrm{C}_{4} \mathrm{H}_{8}$, aromatics, $\mathrm{C} 1-\mathrm{C} 4$ saturated hydrocarbons, $\mathrm{C} 5$ and higher hydrocarbons excluding aromatics. Reaction conditions: $T=470^{\circ} \mathrm{C}$, WHSV $=1 \mathrm{~h}^{-1}, P_{\mathrm{CH}_{3} \mathrm{OH}}=0.5 \mathrm{~atm}, \mathrm{H}_{2} \mathrm{O}: \mathrm{CH}_{3} \mathrm{OH}=1: 1$. Reproduced by permission of Ref. [110]. (Copyright 2008 Elsevier)
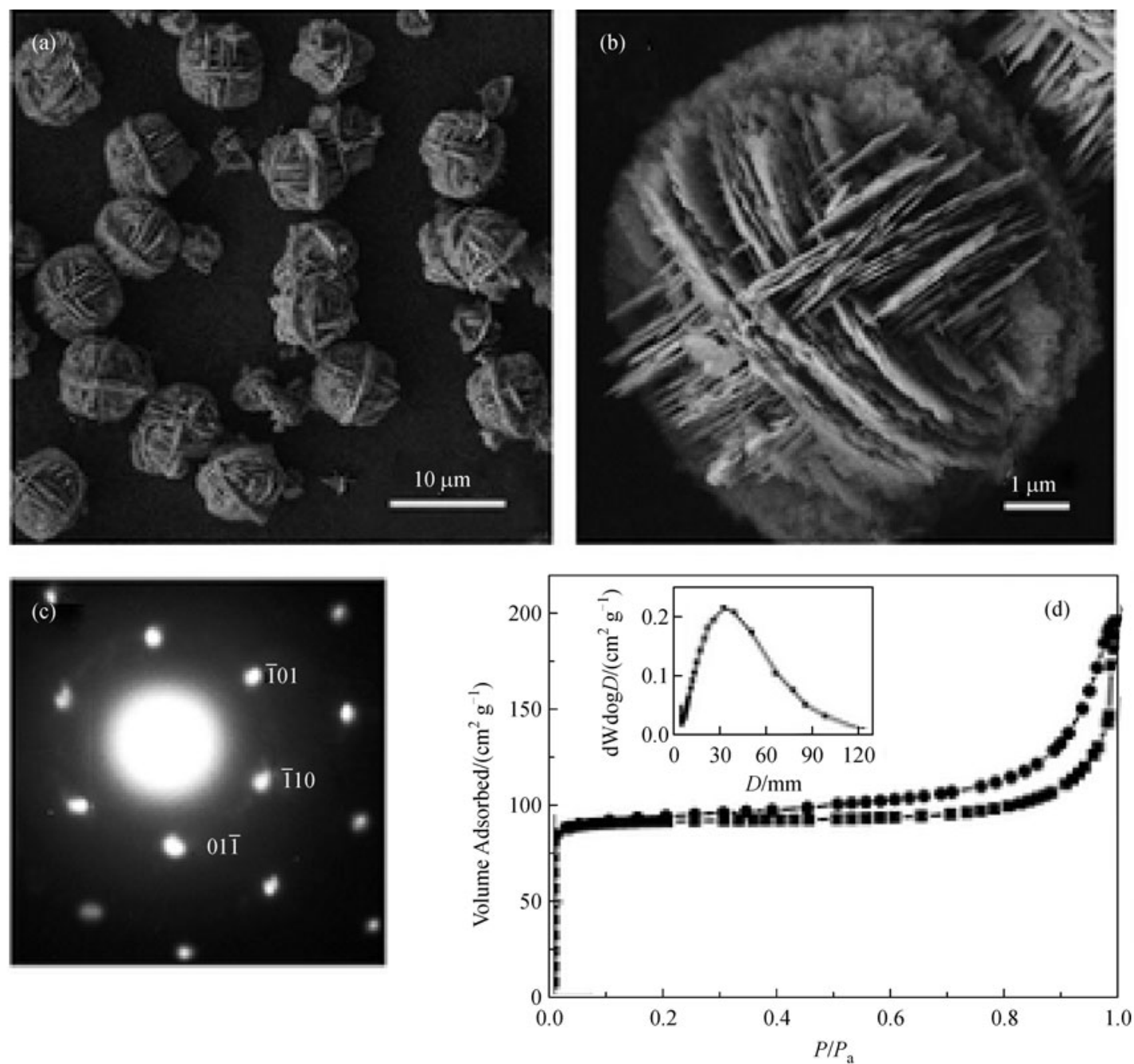

Fig. 11 (a) and (b) SEM images of the hierarchical mesoporous SAPO-34 zeolite at different magnifications; (c) SAED pattern of a horizontal mesoporous zeolite slice; (d) Nitrogen sorption isotherms and BJH pore size distribution (inset). Reproduced by permission of Ref. [111]. (Copyright 2009 Royal Soc Chemistry) 

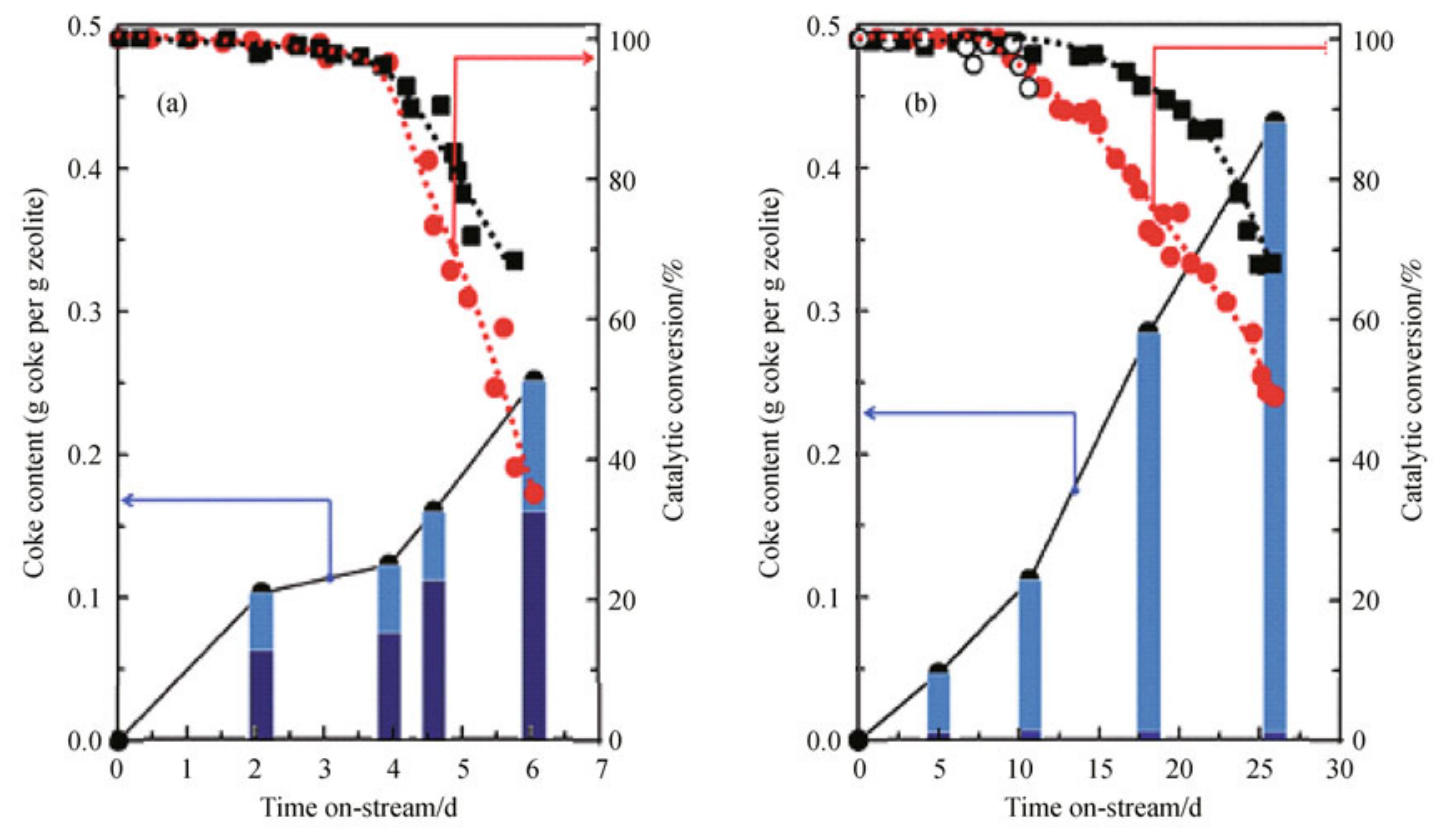

Fig. 12 Coke deposition over (a) conventional MFI zeolite and (b) unilamellar MFI zeolite catalysts during MTG conversion. Catalytic conversion over the unilamellar MFI was repeatedly investigated using three different synthesis batches (red circles, black squares, open circles, respectively). The catalytic measurement for conventional zeolite was repeated twice using the same sample (red circles and black squares). The solid black lines and the dotted red and black lines are guides to the eye. Dark blue bars indicate internal (inside the micropores of the zeolite) coke content, and light blue bars indicate external coke content. Reproduced by permission of [64]. (Copyright 2009 Nature)

\section{References}

1. Corma A. From microporous to mesoporous molecular sieve materials and their use in catalysis. Chemical Reviews, 1997, 97 (6): 2373-2420

2. Davis M E. Ordered porous materials for emerging applications. Nature, 2002, 417(6891): 813-821

3. Cundy C S, Cox P A. The hydrothermal synthesis of zeolites: History and development from the earliest days to the present time. Chemical Reviews, 2003, 103(3): 663-702

4. Hartmann M. Hierarchical zeolites: A proven strategy to combine shape selectivity with efficient mass transport. Angewandte Chemie International Edition, 2004, 43(44): 5880-5882

5. Perez-Ramirez J, Kapteijn F, Groen J C, Domenech A, Mul G, Moulijn J A. Steam-activated FeMFI zeolites. Evolution of iron species and activity in direct $\mathrm{N}_{2} \mathrm{O}$ decomposition. Journal of Catalysis, 2003, 214(1): 33-45

6. Kresge C T, Leonowicz M E, Roth W J, Vartuli J C, Beck J S. Ordered mesoporous molecular-sieves synthesized by a liquidcrystal template mechanism. Nature, 1992, 359(6397): 710-712

7. Beck J S, Vartuli J C, Roth W J, Leonowicz M E, Kresge C T, Schmitt K D, Chu C T W, Olson D H, Sheppard E W, McCullen S B, Higgins J B, Schlenker J L. A new family of mesoporous molecular-sieves prepared with liquid-crystal templates. Journal of the American Chemical Society, 1992, 114(27): 10834-10843

8. Zhao D Y, Feng J L, Huo Q S, Melosh N, Fredrickson G H,
Chmelka B F, Stucky G D. Triblock copolymer syntheses of mesoporous silica with periodic 50 to 300 angstrom pores. Science, 1998, 279(5350): 548-552

9. Zhao D Y, Huo Q S, Feng J L, Chmelka B F, Stucky G D. Nonionic triblock and star diblock copolymer and oligomeric surfactant syntheses of highly ordered, hydrothermally stable, mesoporous silica structures. Journal of the American Chemical Society, 1998, 120(24): 6024-6036

10. Davis M E. Introduction to large-pore molecular-sieves. Catalysis Today, 1994, 19(1): 1-5

11. Liu Y, Zhang W Z, Pinnavaia T J. Steam-stable aluminosilicate mesostructures assembled from zeolite type Y seeds. Journal of the American Chemical Society, 2000, 122(36): 8791-8792

12. Liu Y, Zhang W Z, Pinnavaia T J. Steam-stable MSU-S aluminosilicate mesostructures assembled from zeolite ZSM-5 and zeolite beta seeds. Angewandte Chemie International Edition, 2001, 40(7): 1255-1258

13. Zhang Z T, Han Y, Zhu L, Wang R W, Yu Y, Qiu S L, Zhao D Y, Xiao F S. Strongly acidic and high-temperature hydrothermally stable mesoporous aluminosilicates with ordered hexagonal structure. Angewandte Chemie International Edition, 2001, 40 (7): 1258-1262

14. Xiao F S, Han Y, Yu Y, Meng X J, Yang M, Wu S. Hydrothermally stable ordered mesoporous titanosilicates with highly active catalytic sites. Journal of the American Chemical Society, 2002, 124(6): 888-889

15. Han Y, Li D F, Zhao L, Song J W, Yang X Y, Li N, Di Y, Li C J, 
Wu S, Xu X Z, Meng X J, Lin K F, Xiao F S. High-temperature generalized synthesis of stable ordered mesoporous silica-based materials by using fluorocarbon-hydrocarbon surfactant mixtures. Angewandte Chemie International Edition, 2003, 42(31): 36333637

16. Li D F, Han Y, Song J W, Zhao L, Xu X Z, Di Y, Xiao F S. Hightemperature synthesis of stable ordered mesoporous silica materials by using fluorocarbon-hydrocarbon surfactant mixtures. Chemistry (Weinheim an der Bergstrasse, Germany), 2004, 10(23): 5911-5922

17. Tao Y S, Kanoh H, Abrams L, Kaneko K. Mesopore-modified zeolites: Preparation, characterization, and applications. Chemical Reviews, 2006, 106(3): 896-910

18. Xia Y D, Mokaya R. Are mesoporous silicas and aluminosilicas assembled from zeolite seeds inherently hydrothermally stable? Comparative evaluation of MCM-48 materials assembled from zeolite seeds. Journal of Materials Chemistry, 2004, 14(23): 34273435

19. Tosheva L, Valtchev V P. Nanozeolites: Synthesis, crystallization mechanism, and applications. Chemistry of Materials, 2005, 17 (10): 2494-2513

20. Schoeman B J, Sterte J, Otterstedt J E. Colloid Zeolite Suspensions. Zeolites, 1994, 14(2): 110-116

21. Freyhardt C C, Tsapatsis M, Lobo R F, Balkus K J Jr, Davis M E. A high-silica zeolite with a 14-tetrahedral-atom pore opening. Nature, 1996, 381(6580): 295-298

22. Davis M E, Saldarriaga C, Montes C, Garces J, Crowder C. A molecular-sieve with 18-membered rings. Nature, 1988, 331 (6158): 698-699

23. Corma A, Diaz-Cabanas M J, Jorda J L, Martinez C, Moliner M. High-throughput synthesis and catalytic properties of a molecular sieve with 18- and 10-member rings. Nature, 2006, 443(7113): 842-845

24. Huo Q H, Xu R R, Li S G, Ma Z G, Thomas J M, Jones R H, Chippindale A M. Synthesis and characterization of a novel extra large ring of aluminophosphate JDF-20. Journal of the Chemical Society. Chemical Communications, 1992, (12): 875-876

25. Sun J L, Bonneau C, Cantin A, Corma A, Diaz-Cabanas M J, Moliner M, Zhang D L, Li M R, Zou X D. The ITQ-37 mesoporous chiral zeolite. Nature, 2009, 458(7242): 1154-1157

26. Jiang J X, Jorda J L, Yu J H, Baumes L A, Mugnaioli E, DiazCabanas M J, Kolb U, Corma A. Synthesis and structure determination of the hierarchical meso-microporous zeolite ITQ43. Science, 2011, 333(6046): 1131-1134

27. Meng X J, Nawaz F, Xiao F S. Templating route for synthesizing mesoporous zeolites with improved catalytic properties. Nano Today, 2009, 4(4): 292-301

28. van Donk S, Janssen A H, Bitter J H, de Jong K P. Generation, characterization, and impact of mesopores in zeolite catalysts. Catalysis Reviews. Science and Engineering, 2003, 45(2): 297319

29. Perez-Ramirez J, Christensen C H, Egeblad K, Christensen C H, Groen J C. Hierarchical zeolites: enhanced utilisation of microporous crystals in catalysis by advances in materials design. Chemical Society Reviews, 2008, 37(11): 2530-2542

30. Egeblad K, Christensen $\mathrm{C} \mathrm{H}$, Kustova M, Christensen C H.
Templating mesoporous zeolites. Chemistry of Materials, 2008, 20 (3): 946-960

31. Chal R, Gerardin C, Bulut M, van Donk S. Overview and industrial assessment of synthesis strategies towards zeolites with mesopores. ChemCatChem, 2011, 3(1): 67-81

32. Holm M S, Taarning E, Egeblad K, Christensen C H. Catalysis with hierarchical zeolites. Catalysis Today, 2011, 168(1): 3-16

33. Lynch J, Raatz F, Dufresne P. Characterization of the textural properties of dealuminated HY forms. Zeolites, 1987, 7(4): 333340

34. Triantafillidis C S, Vlessidis A G, Evmiridis N P. Dealuminated HY zeolites: Influence of the degree and the type of dealumination method on the structural and acidic characteristics of H-Y zeolites. Industrial \& Engineering Chemistry Research, 2000, 39(2): 307319

35. Groen J C, Bach T, Ziese U, Donk A M P V, de Jong K P, Moulijn J A, Perez-Ramirez J. Creation of hollow zeolite architectures by controlled desilication of Al-zoned ZSM-5 crystals. Journal of the American Chemical Society, 2005, 127(31): 10792-10793

36. Jacobsen C J H, Madsen C, Houzvicka J, Schmidt I, Carlsson A. Mesoporous zeolite single crystals. Journal of the American Chemical Society, 2000, 122(29): 7116-7117

37. Kustova M, Hasselriis P, Christensen C H. Mesoporous MEL-type zeolite single crystal catalysts. Catalysis Letters, 2004, 96(3-4): 205-211

38. Wei X, Smirniotis P G. Synthesis and characterization of mesoporous ZSM-12 by using carbon particles. Microporous and Mesoporous Materials, 2006, 89(1-3): 170-178

39. Schmidt I, Boisen A, Gustavsson E, Stahl K, Pehrson S, Dahl S, Carlsson A, Jacobsen C J H. Carbon nanotube templated growth of mesoporous zeolite single crystals. Chemistry of Materials, 2001, 13(12): 4416-4418

40. Boisen A, Schmidt I, Carlsson A, Dahl S, Brorson M, Jacobsen C J H. TEM stereo-imaging of mesoporous zeolite single crystals. Chemical Communications, 2003, (8): 958-959

41. Janssen A H, Schmidt I, Jacobsen C J H, Koster A J, de Jong K P. Exploratory study of mesopore templating with carbon during zeolite synthesis. Microporous and Mesoporous Materials, 2003, 65(1): 59-75

42. Tao Y S, Kanoh H, Kaneko K. ZSM-5 monolith of uniform mesoporous channels. Journal of the American Chemical Society, 2003, 125(20): 6044-6045

43. Tao Y S, Kanoh H, Kaneko K. Uniform mesopore-donated zeolite $\mathrm{Y}$ using carbon aerogel templating. Journal of Physical Chemistry B, 2003, 107(40): 10974-10976

44. Tao Y S, Kanoh H, Kaneko K. Synthesis of mesoporous zeolite a by resorcinol-formaldehyde aerogel templating. Langmuir, 2005, 21(2): 504-507

45. Tao Y S, Hattori Y, Matumoto A, Kaneko K. Comparative study on pore structures of mesoporous ZSM-5 from resorcinolformaldehyde aerogel and carbon aerogel templating. Journal of Physical Chemistry B, 2005, 109(1): 194-199

46. Cho S I, Choi S D, Kim J H, Kim G J. Synthesis of zsm-5 films and monoliths with bimodal micro/mesoscopic structures. Advanced Functional Materials, 2004, 14(1): 49-54

47. Yang Z X, Xia Y D, Mokya R. Zeolite ZSM-5 with unique 
supermicropores synthesized using mesoporous carbon as a template. Advanced Materials, 2004, 16(8): 727-732

48. Sakhtivel A, Huang S J, Chen W H, Lan Z H, Chen K H, Kim T W, Ryoo R, Chiang A S T, Liu S B. Replication of mesoporous aluminosilicate molecular sieves (RMMs) with zeolite framework from mesoporous carbons (CMKs). Chemistry of Materials, 2004, 16(16): 3168-3175

49. Fan W, Synder M A, Kumar S, Lee P S, Yoo W C, McCormick A V, Penn R L, Stein A, Tsapatsis M. Hierarchical nanofabrication of microporous crystals with ordered mesoporosity. Nature Materials, 2008, 7(12): 984-991

50. Lee P S, Zhang X Y, Stoeger J A, Malek A, Fan W, Kumar S, Yoo W C, Al Hashimi S, Penn R L, Stein A, Tsapatsis M. Sub-40 nm zeolite suspensions via disassembly of three-dimensionally ordered mesoporous-imprinted silicalite-1. Journal of the American Chemical Society, 2011, 133(3): 493-502

51. Chen H Y, Wydra J, Zhang X Y, Lee P S, Wang Z P, Fan W, Tsapatsis M. Hydrothermal synthesis of zeolites with threedimensionally ordered mesoporous-imprinted structure. Journal of the American Chemical Society, 2011, 133(32): 12390-12393 doi: 10.1021/ja2046815 Fan WTsapatsis M

52. Li H C, Sakamoto Y, Liu Z, Ohsuna T, Terasaki O, Thommes M, Che S N. Mesoporous silicalite-1 zeolite crystals with unique pore shapes analogous to the morphology. Microporous and Mesoporous Materials, 2007, 106(1-3): 174-179

53. Cho H S, Ryoo R. Synthesis of ordered mesoporous MFI zeolite using CMK carbon templates. Microporous and Mesoporous Materials, 2012, 151: 107-112

54. Zhu H, Liu Z, Wang Y, Kong D, Yuan X, Xie Z. Nanosized $\mathrm{CaCO}_{3}$ as hard template for creation of intracrystal pores within silicalite-1 crystal. Chemistry of Materials, 2008, 20(3): 1134-1139

55. Xiao F S, Wang L F, Yin C Y, Lin K F, Di Y, Li J X, Xu R R, Su D $\mathrm{S}$, Schlogl R, Yokoi T, Tatsumi T. Catalytic properties of hierarchical mesoporous zeolites templated with a mixture of small organic ammonium salts and mesoscale cationic polymers. Angewandte Chemie International Edition, 2006, 45(19): 30903093

56. Choi M, Cho H S, Srivastava R, Venkatesan C, Choi D H, Ryoo R. Amphiphilic organosilane-directed synthesis of crystalline zeolite with tunable mesoporosity. Nature Materials, 2006, 5(9): 718723

57. Choi M, Srivastava R, Ryoo R. Organosilane surfactant-directed synthesis of mesoporous aluminophosphates constructed with crystalline microporous frameworks. Chemical Communications, 2006, (42): 4380-4382

58. Srivastava R, Choi M, Ryoo R. Mesoporous materials with zeolite framework: remarkable effect of the hierarchical structure for retardation of catalyst deactivation. Chemical Communications, 2006, (43): 4489-4491

59. Wang H, Pinnavaia T J. MFI zeolite with small and uniform intracrystal mesopores. Angewandte Chemie International Edition, 2006, 45(45): 7603-7606

60. Zhu H B, Liu Z C, Kong D J, Wang Y D, Xie Z K. Synthesis and catalytic performances of mesoporous zeolites templated by polyvinyl butyral gel as the mesopore directing agent. Journal of Physical Chemistry C, 2008, 112(44): 17257-17264
61. Fu W Q, Zhang L, Tang T D, Ke Q P, Wang S, Hu J B, Fang G Y, Li J X, Xiao F S. Extraordinarily high activity in the hydrodesulfurization of 4,6-dimethyldibenzothiophene over Pd supported on mesoporous zeolite Y. Journal of the American Chemical Society, 2011, 133(39): 15346-15349

62. Zhu Y, Hua Z L, Zhou J, Wang L J, Zhao J J, Gong Y, Wu W, Ruan M L, Shi J L. Hierarchical mesoporous zeolites: Direct selfAssembly synthesis in a conventional surfactant solution by kinetic control over the zeolite seed formation. Chemistry (Weinheim an der Bergstrasse, Germany), 2011, 17(51): 14618-14627

63. Zhou J, Hua Z L, Liu Z C, Wu W, Zhu Y, Shi J L. Direct synthetic strategy of mesoporous ZSM-5 zeolites by using conventional block copolymer templates and the improved catalytic properties. Acs Catalysis, 2011, 1(4): 287-291

64. Choi M, Na K, Kim J, Sakamoto Y, Terasaki O, Ryoo R. Stable single-unit-cell nanosheets of zeolite MFI as active and long-lived catalysts. Nature, 2009, 461(7261): 246-250

65. Na K, Choi M, Park W, Sakamoto Y, Terasaki O, Ryoo R. Pillared MFI zeolite nanosheets of a single-unit-cell thickness. Journal of the American Chemical Society, 2010, 132(12): 4169-4177

66. Na K, Jo C, Kim J, Cho K, Jung J, Seo Y, Messinger R J, Chmelka B F, Ryoo R. Directing zeolite structures into hierarchically nanoporous architectures. Science, 2011, 333(6040): 328-332

67. Liu F J, Willhammar T, Wang L, Zhu L F, Sun Q, Meng X J, Carrillo-Cabrera W, Zou X D, Xiao F S. ZSM-5 zeolite single crystals with b-axis-aligned mesoporous channels as an efficient catalyst for conversion of bulky organic molecules. Journal of the American Chemical Society, 2012, 134(10): 4557-4560

68. Kung H H, Williams B A, Babitz S M, Miller J T, Haag W O, Snurr R Q. Enhanced hydrocarbon cracking activity of Y zeolites. Topics in Catalysis, 2000, 10(1-2): 59-64

69. Haag W O, Lago R M, Weisz P B. Transport and reactivity of hydrocarbon molecules in a shape-selective zeolite. Faraday Discussions, 1981, 72: 317-330

70. Garcia-Martinez J, Johnson M, Valla J, Li K H, Ying J Y. Mesostructured zeolite Y-high hydrothermal stability and superior FCC catalytic performance. Catalysis Science \& Technology, 2012, 2(5): 987-994

71. Tan Q F, Fan Y, Liu H Y, Song T C, Shi G, Shen B J, Bao X. Bimodal micro-mesoporous aluminosilicates for heavy oil cracking: Porosity tuning and catalytic properties. AIChE Journal. American Institute of Chemical Engineers, 2008, 54(7): 18501859Bao X J

72. Siddiqui M A B, Aitani A M, Saeed M R, Al-Yassir N, Al-Khattaf S. Enhancing propylene production from catalytic cracking of Arabian Light VGO over novel zeolites as FCC catalyst additives. Fuel, 2011, 90(2): 459-466

73. Park D H, Kim S S, Wang H, Pinnavaia T J, Papapetrou M C, Lappas A A, Triantafyllidis K S. Selective petroleum refining over a zeolite catalyst with small intracrystal mesopores. Angewandte Chemie International Edition, 2009, 48(41): 7645-7648

74. Wang L F, Yin C Y, Shan Z C, Liu S, Du Y C, Xiao F S. Breadtemplate synthesis of hierarchical mesoporous ZSM-5 zeolite with hydrothermally stable mesoporosity. Colloids and Surfaces A, 2009, 340(1-3): 126-130

75. Lei Q, Zhao T B, Li F Y, Zhang L L, Wang Y. Catalytic cracking of 
large molecules over hierarchical zeolites. Chemical Communications (Cambridge), 2006, (16): 1769-1771

76. Christensen $\mathrm{C} \mathrm{H}$, Schmidt I, Christensen $\mathrm{C} \mathrm{H}$. Improved performance of mesoporous zeolite single crystals in catalytic cracking and isomerization of $n$-hexadecane. Catalysis Communications, 2004, 5(9): 543-546

77. Kustova M, Egeblad K, Christensen C H, Kustov A L, Christensen $\mathrm{C}$ H. Hierarchical zeolites: Progress on synthesis and characterization of mesoporous zeolite single crystal catalysts. Studies in Surface Science and Catalysis, 2007, 170: 267-275

78. Kustova M Y, Hasselriis P, Christensen C H. Mesoporous MELtype zeolite single crystal catalysts. Catalysis Letters, 2004, 96(34): 205-211

79. Shetti V N, Kim J, Srivastava R, Choi M, Ryoo R. Assessment of the mesopore wall catalytic activities of MFI zeolite with mesoporous/microporous hierarchical structures. Journal of Catalysis, 2008, 254(2): 296-303

80. Christensen C H, Johannsen K, Schmidt I, Christensen C H. Catalytic benzene alkylation over mesoporous zeolite single crystals: Improving activity and selectivity with a new family of porous materials. Journal of the American Chemical Society, 2003, 125(44): 13370-13371

81. Christensen C H, Johannsen K, Toernqvist E, Schmidt I, Topsoe H, Christensen C H. Mesoporous zeolite single crystal catalysts: Diffusion and catalysis in hierarchical zeolites. Catalysis Today, 2007, 128(1-2): 117-122

82. Perez-Ramirez J, Verboekend D, Bonilla A, Abello S. Zeolite Catalysts with tunable hierarchy factor by pore-growth moderators. Advanced Functional Materials, 2009, 19(24): 3972-3979

83. van Iaak A N C, Gosselink R W, Sagala S L, Meeldijk J D, de Jongh $\mathrm{P}$ E, de Jong K P. Alkaline treatment on commercially available aluminum rich mordenite. Applied Catalysis A, General, 2010, 382(1): 65-72

84. van Laak A N C, Sagala S L, Zecevic J, Friedrich H, de Jongh P E, de Jong K P. Mesoporous mordenites obtained by sequential acid and alkaline treatments - Catalysts for cumene production with enhanced accessibility. Journal of Catalysis, 2010, 276(1): 170180

85. Pellet R J, Casey D G, Huang H M, Kessler R V, Kuhlman E J, Oyoung C L, Sawicki R A, Ugolini J R. Isomerization of $n$-butene to isobutene by ferrierite and modified ferrierite catalysts. Journal of Catalysis, 1995, 157(2): 423-435

86. Khitev Y P, Kolyagin Y G, Ivanova I I, Ponomareva O A, Thibault-Starzyk F, Gilson J P, Fernandez C, Fajula F. Synthesis and catalytic properties of hierarchical micro/mesoporous materials based on FER zeolite. Microporous and Mesoporous Materials, 2011, 146(1-3): 201-207

87. Matias P, Couto C S, Graca I, Lopes J M, Carvalho A P, Ribeiro F $\mathrm{R}$, Guisnet M. Desilication of a TON zeolite with $\mathrm{NaOH}$ : Influence on porosity, acidity and catalytic properties. Applied Catalysis A, General, 2011, 399(1-2): 100-109

88. van Donk S, Broersma A, Gijzeman O L J, van Bokhoven J A, Bitter J H, de Jong K P. Combined diffusion, adsorption, and reaction studies of $n$-hexane hydroisomerization over $\mathrm{Pt} / \mathrm{H}$ mordenite in an oscillating microbalance. Journal of Catalysis, 2001, 204(2): 272-280
89. Chao P H, Tsai S T, Chang S L, Wang I, Tsai T C. Hexane isomerization over hierarchical Pt/MFI zeolite. Topics in Catalysis, 2010, 53(1-2): 231-237

90. Modhera B K, Chakraborty M, Bajaj H C, Parikh P A. Influences of mesoporosity generation in ZSM-5 and zeolite beta on catalytic performance during $n$-hexane isomerization. Catalysis Letters, 2011, 141(8): 1182-1190

91. Moushey D L, Smirniotis P G. $n$-Heptane hydroisomerization over mesoporous zeolites made by utilizing carbon particles as the template for mesoporosity. Catalysis Letters, 2009, 129(1-2): 2025

92. Verboekend D, Thomas K, Milina M, Mitchell S, Perez-Ramirez J, Gilson J P. Towards more efficient monodimensional zeolite catalysts: $n$-Alkane hydro-isomerisation on hierarchical ZSM-22. Catalysis Science \& Technology, 2011, 1(8): 1331-1335

93. Fan Y, Xiao H, Shi G, Liu H Y, Bao X J. Alkylphosphonic acidand small amine-templated synthesis of hierarchical silicoaluminophosphate molecular sieves with high isomerization selectivity to di-branched paraffins. Journal of Catalysis, 2012, 285(1): 251259

94. Qin B, Zhang X W, Zhang Z Z, Ling F X, Sun W F. Synthesis, characterization and catalytic properties of Y-beta zeolite composites. Petroleum Science, 2011, 8(2): 224-228

95. Chica A, Diaz U, Fornes V, Corma A. Changing the hydroisomerization to hydrocracking ratio of long chain alkanes by varying the level of delamination in zeolitic (ITQ-6) materials. Catalysis Today, 2009, 147(3-4): 179-185

96. Fernandez C, Stan I, Gilson J P, Thomas K, Vicente A, Bonilla A, Perez-Ramirez J. Hierarchical ZSM-5 zeolites in shape-selective xylene isomerization: Role of mesoporosity and acid site speciation. Chemistry (Weinheim an der Bergstrasse, Germany), 2010, 16(21): 6224-6233

97. Mihalyi R M, Kollar M, Kiraly P, Karoly Z, Mavrodinova V. Effect of extra-framework $\mathrm{Al}$ formed by successive steaming and acid leaching of zeolite MCM-22 on its structure and catalytic performance. Applied Catalysis A, General, 2012, 417: 76-86

98. Tang T D, Yin C Y, Wang L F, Ji Y Y, Xiao F S. Superior performance in deep saturation of bulky aromatic pyrene over acidic mesoporous beta zeolite-supported palladium catalyst. Journal of Catalysis, 2007, 249(1): 111-115

99. Tang T D, Yin C Y, Wang L F, Ji Y Y, Xiao F S. Good sulfur tolerance of a mesoporous beta zeolite-supported palladium catalyst in the deep hydrogenation of aromatics. Journal of Catalysis, 2008, 257(1): 125-133

100. Sun Y Y, Prins R. Hydrodesulfurization of 4,6-dimethyldibenzothiophene over noble metals supported on mesoporous zeolites. Angewandte Chemie International Edition, 2008, 47(44): 84788481

101. Zheng J J, Zeng Q H, Zhang Y Y, Wang Y, Ma J H, Zhang X W, Sun W F, Li R F. Hierarchical porous zeolite composite with a core-shell structure fabricated using beta-zeolite crystals as nutrients as well as cores. Chemistry of Materials, 2010, 22(22): 6065-6074

102. Xu Y D, Lin L W. Recent advances in methane dehydroaromatization over transition metal ion-modified zeolite catalysts under non-oxidative conditions. Applied Catalysis A, General, 
1999, 188(1-2): 53-67

103. Su L L, Liu L, Zhuang J Q, Wang H X, Li Y G, Shen W J, Xu Y D, Bao X H. Creating mesopores in ZSM-5 zeolite by alkali treatment: A new way to enhance the catalytic performance of methane dehydroaromatization on Mo/HZSM-5 catalysts. Catalysis Letters, 2003, 91(3-4): 155-167

104. Chu N B, Yang J H, Li C Y, Cui J Y, Zhao Q Y, Yin X Y, Lu J M, Wang J Q. An unusual hierarchical ZSM-5 microsphere with good catalytic performance in methane dehydroaromatization. Microporous and Mesoporous Materials, 2009, 118(1-3): 169175

105. Martinez A, Peris E, Derewinski M, Burkat-Dulak A. Improvement of catalyst stability during methane dehydroaromatization (MDA) on Mo/HZSM-5 comprising intracrystalline mesopores. Catalysis Today, 2011, 169(1): 75-84

106. Liu H, Yang S, Hu J, Shang F P, Li Z F, Xu C, Guan J Q, Kan Q B. A comparison study of mesoporous Mo/H-ZSM-5 and catalysts in methane non-oxidative aromatization. Fuel Processing Technology, 2012, 96: 195-202

107. Chu N B, Wang J Q, Zhang Y, Yang J H, Lu J M, Yin D H. Nestlike hollow hierarchical MCM-22 microspheres: synthesis and exceptional catalytic properties. Chemistry of Materials, 2010, 22(9): $2757-2763$

108. Tang Q, Xu H, Zheng Y Y, Wang J F, Li H S, Zhang J. Zhang Jun. Catalytic dehydration of methanol to dimethyl ether over micromesoporous ZSM-5/MCM-41 composite molecular sieves. Applied Catalysis A, General, 2012, 413: 36-42

109. Cho K, Cho H S, de Menorval L C, Ryoo R. Generation of mesoporosity in LTA zeolites by organosilane surfactant for rapid molecular transport in catalytic application. Chemistry of Materials, 2009, 21(23): 5664-5673

110. Mei C S, Wen P Y, Liu Z C, Liu H X, Wang Y D, Yang W M, Xie Z K, Hua W M, Gao Z. Selective production of propylene from methanol: Mesoporosity development in high silica HZSM-5. Journal of Catalysis, 2008, 258(1): 243-249

111. Zhu J, Cui Y, Wang Y, Wei F. Direct synthesis of hierarchical zeolite from a natural layered material. Chemical Communications, 2009, (22): 3282-3284

112. Wang P F, Lv A L, Hu J, Xu J A, Lu G Z. In situ synthesis of SAPO-34 grown onto fully calcined kaolin microspheres and its catalytic properties for the MTO reaction. Industrial \& Engineering Chemistry Research, 2011, 50(17): 9989-9997

113. Olsbye U, Svelle S, Bjorgen M, Beato P, Janssens T V W, Joensen F, Bordiga S, Lillerud K P. Conversion of methanol to hydrocarbons: How zeolite cavity and pore size controls product selectivity. Angewandte Chemie International Edition, 2012, 51 (24): 5810-5831

114. Lietz G, Schnabel K H, Peuker C, Gross T, Storek W, Volter J. Modifications of H-ZSM- 5 catalysts by $\mathrm{NaOH}$ treatment. Journal of Catalysis, 1994, 148(2): 562-568

115. Bjorgen M, Joensen F, Holm M S, Olsbye U, Lillerud K P, Svelle S. Methanol to gasoline over zeolite H-ZSM-5: Improved catalyst performance by treatment with $\mathrm{NaOH}$. Applied Catalysis A, General, 2008, 345(1): 43-50

116. Kim J, Choi M, Ryoo R. Effect of mesoporosity against the deactivation of MFI zeolite catalyst during the methanol-tohydrocarbon conversion process. Journal of Catalysis, 2010, 269 (1): 219-228

117. Ni Y M, Sun A M, Wu X L, Hai G L, Hu J L, Li T, Li G X. Preparation of hierarchical mesoporous Zn/HZSM-5 catalyst and its application in MTG reaction. Journal of Natural Gas Chemistry, 2011, 20(3): 237-242

118. Rownaghi A A, Hedlund J. Methanol to gasoline-range hydrocarbons: Influence of nanocrystal size and mesoporosity on catalytic performance and product distribution of ZSM-5. Industrial \& Engineering Chemistry Research, 2011, 50(21): 1187211878

119. Vennestrom P N R, Grill M, Kustova M, Egeblad K, Lundegaard L F, Joensen F, Christensen C H, Beato P. Hierarchical ZSM-5 prepared by guanidinium base treatment: Understanding microstructural characteristics and impact on MTG and $\mathrm{NH}_{3}-\mathrm{SCR}$ catalytic reactions. Catalysis Today, 2011, 168(1): 71-79

120. Rownaghi A A, Rezaei F, Hedlund J. Rezaei, Hedlund J. Uniform mesoporous ZSM-5 single crystals catalyst with high resistance to coke formation for methanol deoxygenation. Microporous and Mesoporous Materials, 2012, 151: 26-33

121. Kima K, Ryoo R, Jang H D, Choi M. Spatial distribution, strength, and dealumination behavior of acid sites in nanocrystalline MFI zeolites and their catalytic consequences. Journal of Catalysis, 2012, 288: 115-123 